\title{
The Effect of Substituents on Indirect Nuclear Spin-Spin Coupling Constants: Methan- and Ethanimine, Methanal- and Ethanaloxime
}

\author{
Patricio F. Provasi ${ }^{1}$, Gustavo A. Aucar ${ }^{1 *}$ and Stephan P. A. Sauer ${ }^{2}$ \\ ${ }^{1}$ Department of Physics, Northeastern University, Av. Libertad 5500, W 3404 AAS Corrientes, \\ Argentina \\ ${ }^{2}$ Department of Chemistry, University of Copenhagen, Universitetsparken 5, DK-2100 \\ Copenhagen Ø, Denmark. E-mail: patricio@unne.edu.ar, gaa@unne.edu.ar, sauer@kiku.dk \\ URL: http://fyskem.ki.ku.dk/sauer \\ * Author to whom correspondence should be addressed.
}

Received: 28 October 2002 / Accepted: 17 February 2003 / Published: 4 April 2003

\begin{abstract}
A b$ initio calculations of the spin-spin coupling constants have been carried out for methan- and ethanimine, methanal- and ethanaloxime at the level of the second order polarization propagator approximation with coupled cluster singles and doubles amplitudes (SOPPA(CCSD)) using the aug-cc-pVTZ-J basis sets. Previously we have shown that this method can reproduce quantitatively the coupling constants for methanimine; our new results for methanal- and ethanaloxime agree also very well with the measured couplings. A study of both purely geometrical and substituent effects on all coupling constants in the title compounds is presented. Analyzing the four contributions to the coupling constants we find that the stereoelectronic effect of the nitrogen lone pair on the one-bond $\mathrm{C}-\mathrm{H}$ and $\mathrm{C}-\mathrm{C}$ couplings as well as the corresponding effect for the geminal N-H and N-C couplings is affected strongly by the $-\mathrm{OH}$ substituent. For the one-bond $\mathrm{C}-\mathrm{N}$ couplings we observe that the orbital paramagnetic (OP) contribution is comparable to the Fermi Contact (FC) contribution but opposite in sign and that the spin-dipolar (SD) term amounts to between $40 \%$ and $85 \%$ of the total coupling constants. Changes in the total one-bond C-N couplings caused by the $-\mathrm{OH}$ substituent are also almost entirely due to SD contribution.
\end{abstract}

Keywords: Ab Initio, NMR, indirect nuclear spin-spin coupling constants, SOPPA(CCSD), methanimine, ethanimine, methanaloxime, ethanaloxime. 


\section{Introduction}

In recent years the increasing importance of NMR spectroscopy for the determination of three dimensional structures of even biomolecules [1] leads to an ever increasing demand for very accurate calculations of the spectroscopic parameters defining an NMR spectrum: for instance the chemical shift and the indirect nuclear spin-spin coupling constants of bio-related molecules. Often these molecules are too large for accurate calculations and many authors [2-11] make therefore use of model-systems which are supposed to include the relevant atoms, e.g. the atoms involved in peptide bonds. It is thus often assumed that replacing substituents by hydrogen will not significantly change the results. This might not be true in general. Therefore, we proposed recently the use of locally dense basis sets in the calculation of spin-spin coupling constants $[12,13]$, i.e. to use basis sets optimized for coupling constant calculations [14-16] only on the atoms of interest whereas using smaller standard basis sets on the other atoms. Secondly, we have developed smaller optimized basis sets for coupling constant calculations [16] by contracting the s- and p-type functions in large optimized basis sets [15] with molecular orbital coefficients from self-consistent field calculations on the corresponding hydride molecules $\mathrm{AH}_{\mathrm{n}}$. These two options can be combined in order to increase the maximal size of molecules in coupling constant calculations without a significant loss of accuracy.

The purpose of the present work was therefore to investigate how much the coupling constants in methanimine (1), (E)/(Z)-ethanimine (3)/(4), methanaloxime (2) and (E)/(Z)-ethanaloxime (5)(6) are influenced by replacing one of the hydrogens in the methylen group by a methyl group and by replacing the imine hydrogen by a hydroxyl group. In particular we were interested in the possible interplay of the stereoelectronic effects of the nitrogen lone pair [17-21], e.g. the so-called anomeric $[22,23]$ or negative hyperconjugation effect [24], the positive inductive effect of the methyl group and the positive conjugation effect of the hydroxyl group. We have carried out state of the art ab initio calculations on the above mentioned compounds using the second order polarization propagator approximation with coupled cluster single and double amplitudes (SOPPA(CCSD)) [15,25] and our aug-cc-pVTZ-J basis sets $[15,16]$. Previous applications of this method gave results in very good agreement with experiment [15,16,26-33].

Calculations of coupling constants are sometimes affected by the so-called triplet instabilities or quasi-instabilities [34-36], i.e. the fact that the employed method predicts erroneously the existence of a triplet state which is lower or close in energy to the lowest singlet state (ground state). This phenomenon can lead to an over- or underestimation of the contributions to the coupling constants which involve the electron spin, i.e. the Fermi contact and the spin-dipolar terms. This will render the results of these coupling constant calculations meaningless. Although, instabilities have been observed mainly using semiempirical methods [37-44], there is also an increasing number of examples [15,16,45] for instabilities in ab initio calculations using the coupled Hartree-Fock method (CHF) [46] or the equivalent random phase approximation (RPA) $[47,48]$ and one example for a triplet instability at the correlated level $[15,45]$ using the second order polarization propagator approximation (SOPPA) 
[49]. This phenomenon is connected with the existence of $\pi$-like electronic systems in both saturated and unsaturated compounds. One factor which influence the $\pi$-system in the $\mathrm{C}=\mathrm{N}$ bond is the lone pair on nitrogen. Therefore, we have carried out also CHF/RPA calculations on the title compounds in order to search for triplet instabilities.

\section{Computational Aspects}

The theory of the indirect nuclear spin-spin coupling constant $J$ was originally derived by Ramsey [50] using perturbation theory:

$$
J_{A B}=\frac{\gamma_{A} \gamma_{B}}{3 h} \sum_{\alpha=x, y, z}\left\{\left\langle 0\left|\left(\hat{O}_{A B}^{O D}\right)_{\alpha \alpha}\right| 0\right\rangle+2 \sum_{n \neq 0} \frac{\left\langle 0\left|\left(\hat{\vec{O}}_{A}^{O P}+\hat{\vec{O}}_{A}^{F C}+\hat{\vec{O}}_{A}^{S D}\right)_{\alpha}\right| n\right\rangle\left\langle n\left|\left(\hat{\vec{O}}_{B}^{O P}+\hat{\vec{O}}_{B}^{F C}+\hat{\vec{O}}_{B}^{S D}\right)_{\alpha}\right| 0\right\rangle}{E_{0}-E_{n}}\right\}
$$

where $\gamma_{A}$ and $\gamma_{B}$ are the magnetogyric ratios of the two nuclei $A$ and $B$ and $h$ is the Planck constant [51]. The coupling is transmitted by two basic mechanisms: (a) the interaction of the nuclear spins with the spins of the electrons surrounding them expressed in the Fermi-contact (FC) and spin-dipolar (SD) contributions and (b) the interaction of the nuclear spins with the orbital angular momentum of the electrons which gives rise to the orbital paramagnetic (OP) and orbital diamagnetic (OD) contributions. Due to the interaction with the electron spin the FC and SD terms arise from admixtures of excited triplet states $|n\rangle$ to the singlet ground state $|0\rangle$, whereas the OP term involves excited states $|n\rangle$ of the same spin symmetry as the ground state $|0\rangle$ and the OD term is a pure ground state property, although the latter can also be expressed in a form which involves excited states [52]. Using polarization propagator or linear response function methods all contributions to the coupling constants can be evaluated without explicit calculation of the excited states involved $[53,54]$. The detailed scheme for calculations of indirect nuclear spin-spin coupling constants using polarization propagator methods has been described and explained previously [15,55] and will not be given here. In the present work we have used two levels of approximation to the polarization propagator: SOPPA(CCSD) $[15,25]$ and RPA [47,48], which can also be considered as a first order polarization propagator approximation [53].

In all coupling constant calculations we have used a local version of the DALTON program package [56], in which the calculation of indirect nuclear spin-spin coupling constants at the SOPPA(CCSD) level had been implemented in the property module [15,25]. We have used the aug-ccpVTZ-J basis sets [16,57] for all atoms in methan- and ethanimine, whereas in the calculations on methanal- and ethanaloxime we used a locally dense basis set $[12,13]$ with the cc-pVDZ basis sets [58] on the atoms in the hydroxyl-group and the aug-cc-pVTZ-J basis sets [16,57] on all other atoms. These basis sets were optimized to describe the notorious Fermi contact term properly. They were generated from Dunning's aug-cc-pVTZ basis sets $[58,59]$ by adding four tight s-type functions to the completely 
uncontracted basis sets [15] and re-contracting the most inner s-type function for $\mathrm{H}$ and s- and p-type functions for the second row atoms with corresponding molecular orbital coefficients from selfconsistent field calculations on the second row hydrides [16]. Only the inner atomic orbitals were contracted which made the contraction scheme independent of the molecule under study and gave an easy and general way to reduce the size of the basis sets without diminishing the accuracy of the results. In addition the set of the most diffuse f-type functions on the second row atoms was also removed [15]. A similar idea had been used previously by Geertsen et al. [60] and Guilleme and San Fabián [61] in their calculations on methane.

In Figures 1-3 the optimized geometries for all molecules are shown. They were obtained at the MP2//6-31G** level with the GAUSSIAN 98 program [62]. We can note a small discrepancy between the experimental geometries for (Z)/(E)-ethanimine [63] (3/4) and our optimized ones, which might be a misprint caused by the non-standard definition of cis- and trans- in Ref. [63]. For (Z)-ethanimine (4) the experimentally derived $\angle_{\mathrm{CCN}}$ angle is $121^{\circ}$ and the theoretical one is $128.01^{\circ}$, whereas for (E)ethanimine (3) the experimental angle is $126^{\circ}$ and our optimized value is $120.79^{\circ}$.

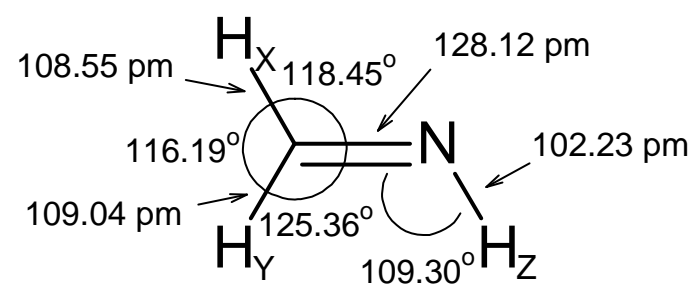

(1)

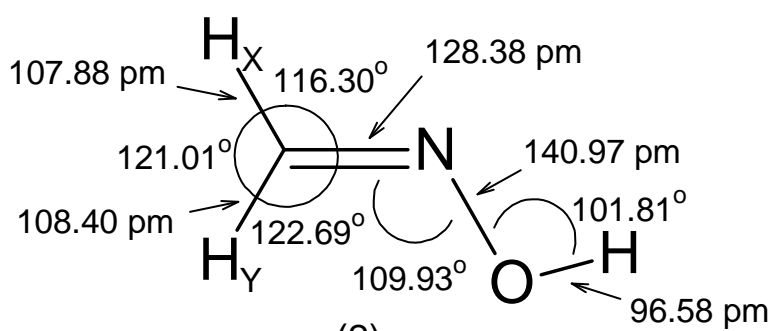

(2)

Figure 1. Optimized MP2/6-31G** geometries of methanimine (1) and methanaloxime (2).

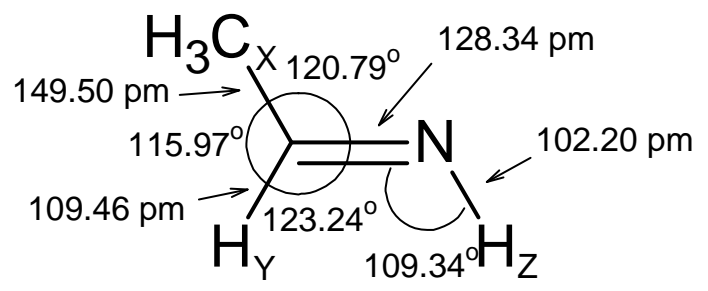

(3)

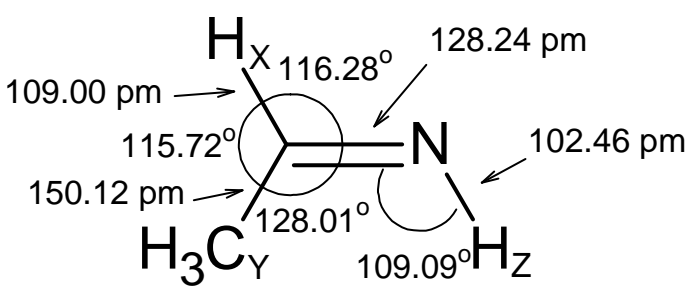

(4)

Figure 2. Optimized MP2/6-31G** geometries of (E)-ethanimine (3) and (Z)-ethanimine (4). One of the $\mathrm{C}-\mathrm{H}$ bonds in the $\mathrm{H}_{3} \mathrm{C}$ - group is eclipsed to the $\mathrm{C}=\mathrm{N}$ bond. 

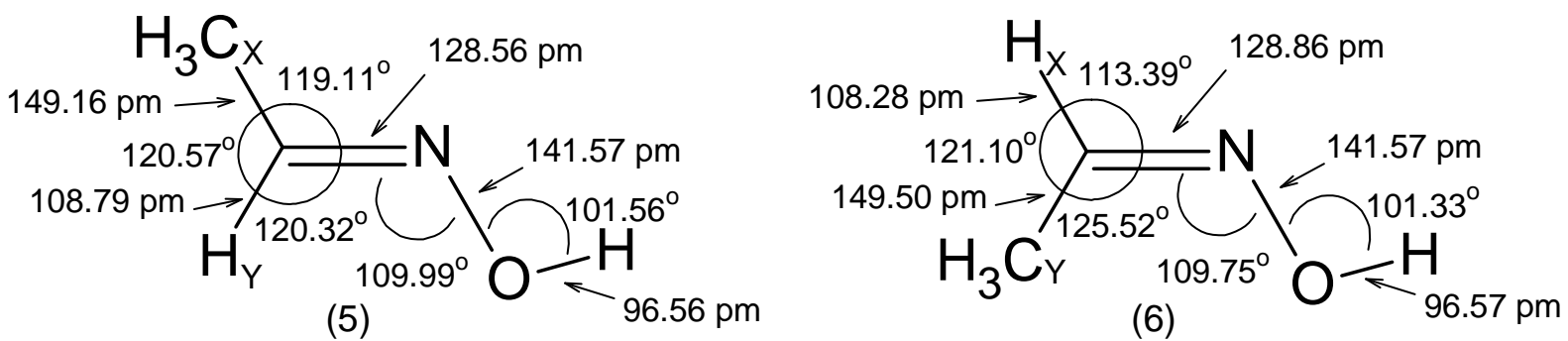

Figure 3. Optimized MP2/6-31G** geometries of the (E)-ethanaloxime (5) and (Z)-ethanaloxime (6). One of the $\mathrm{C}-\mathrm{H}$ bonds in the $\mathrm{H}_{3} \mathrm{C}$ - group is eclipsed to the $\mathrm{C}=\mathrm{N}$ bond in (E)-ethanaloxime, whereas it is eclipsed to the $\mathrm{C}-\mathrm{H}$ bond in the $(\mathrm{Z})$ isomer.

There are some special features about the optimized geometries which we want to stress:

1. The $\mathrm{R}_{\mathrm{CN}}$ bond length is close to $128 \mathrm{pm}$ in all molecules.

2. The substituent $-\mathrm{OH}$ leads to an increase of the $\angle_{\mathrm{XCY}}$ angle by $\sim 5^{\circ}$ and to a decrease of the $\angle_{\mathrm{XCN}}$ and $\angle_{\mathrm{YCN}}$ angles by $2^{\circ}$ to $3^{\circ}$.

3. The $\mathrm{C}=\mathrm{N}-\mathrm{Z}$ group is roughly rigid with respect to both its internal distances and angles.

\section{Results}

In Tables 1, 3, and 4 the results for the one-bond, geminal and vicinal coupling constants in all six molecules are shown. Apart from the total coupling constant $J$ in $\mathrm{Hz}$ we report also the total reduced coupling constant $K$ (in $10^{19} \mathrm{~T}^{2} \mathrm{~J}^{-1}$ ) and its four contributions in order to allow a comparison of analog couplings between different pairs of nuclei. The reduced coupling constant $K$ is commonly defined as

$$
K(\mathrm{~A}, \mathrm{~B})=\frac{1}{h} \frac{2 \pi}{\gamma_{A}} \frac{2 \pi}{\gamma_{B}} J(\mathrm{~A}, \mathrm{~B})
$$

where $\gamma_{A}$ and $\gamma_{B}$ are the magnetogyric ratios of the two nuclei $\mathrm{A}$ and $\mathrm{B}$ and $h$ is the Planck constant [64].

In our previous study [16] of the coupling constants in $\mathrm{CH}_{2} \mathrm{CH}_{2}, \mathrm{CH}_{2} \mathrm{NH}, \mathrm{CH}_{2} \mathrm{O}$ and $\mathrm{CH}_{2} \mathrm{~S}$ we found that our SOPPA(CCSD) coupling constants for methanimine (1) are in very good agreement with the experimental values [65,66], not only the absolute values but also with respect to the differences in couplings syn- or antiperiplanar to the double bond or to the lone pair on nitrogen. Inspection of Tables 1 and 3-4 shows that an equally good agreement between our SOPPA(CCSD) calculations and experiment is also obtained for methanal- [67,68] and ethanaloxime [67,68,69]. Therefore we are confident to discuss the substituent effects on the couplings by analyzing our results in the following sections. In order to separate effects by the $\mathrm{OH}$ substituent from changes in the geometries we have also performed calculations on methanimine and methanaloxime with the angles in the methylengroup taken from the other molecule, see Table 2. 
Table 1. One-bond spin-spin couplings calculated at SOPPA(CCSD) level. Coupling constants, $J$, in $\mathrm{Hz}$ and reduced coupling constants, $K$, in $10^{19} \mathrm{~T}^{2} \mathrm{~J}^{-1}$.

\begin{tabular}{|c|c|c|c|c|c|c|c|c|}
\hline Coupling & Molecule & $K^{\mathrm{OD}}$ & $K^{\mathrm{OP}}$ & $K^{\mathrm{SD}}$ & $K^{\mathrm{FC}}$ & $K$ & $J$ & $J^{\text {expt. }}$ \\
\hline \multirow[t]{6}{*}{$\mathrm{C}-{ }^{15} \mathrm{~N}$} & methanimine & 0.04 & -28.07 & 4.59 & 30.75 & 7.30 & -2.23 & \\
\hline & (Z)-ethanimine & 0.11 & -26.70 & 4.49 & 28.51 & 6.41 & -1.96 & \\
\hline & (E)-ethanimine & 0.11 & -27.02 & 4.40 & 33.16 & 10.65 & -3.26 & \\
\hline & methanaloxime & 0.14 & -26.71 & 8.20 & 30.62 & 12.25 & -3.75 & $|2.96|[68]^{\mathrm{a}}$ \\
\hline & (Z)-ethanaloxime & 0.21 & -26.68 & 7.69 & 27.88 & 9.10 & -2.79 & $|2.3|[68]^{\mathrm{a}}$ \\
\hline & (E)-ethanaloxime & 0.21 & -26.34 & 7.99 & 32.59 & 14.46 & -4.43 & $|4.0|[68]^{\mathrm{a}}$ \\
\hline \multirow[t]{3}{*}{${ }^{15} \mathrm{~N}-\mathrm{H}_{\mathrm{Z}}$} & methanimine & 0.11 & 0.43 & -0.14 & 40.15 & 40.55 & -49.39 & \\
\hline & (Z)-ethanimine & 0.15 & 0.72 & -0.13 & 39.45 & 40.19 & -48.95 & \\
\hline & (E)-ethanimine & 0.14 & 0.71 & -0.11 & 40.92 & 41.65 & -50.73 & \\
\hline \multirow[t]{4}{*}{$\mathrm{C}-\mathrm{H}_{\mathrm{X}}$} & methanimine & 0.16 & -0.12 & 0.04 & 56.80 & 56.89 & 171.86 & $172.9[65]$ \\
\hline & (Z)-ethanimine & 0.25 & -0.19 & 0.03 & 55.08 & 55.17 & 166.68 & \\
\hline & methanaloxime & 0.20 & -0.01 & -0.01 & 58.72 & 58.90 & 177.95 & \\
\hline & (Z)-ethanaloxime & 0.28 & -0.09 & -0.02 & 57.77 & 57.94 & 175.05 & $177 \pm 1[69]$ \\
\hline \multirow[t]{4}{*}{$\mathrm{C}-\mathrm{H}_{\mathrm{Y}}$} & methanimine & 0.16 & -0.09 & 0.05 & 52.86 & 52.99 & 160.07 & $163.7[66]$ \\
\hline & (E)-ethanimine & 0.25 & -0.18 & 0.04 & 51.66 & 51.77 & 156.41 & \\
\hline & methanaloxime & 0.22 & -0.04 & 0.03 & 55.60 & 55.81 & 168.60 & \\
\hline & (E)-ethanaloxime & 0.30 & -0.12 & 0.02 & 54.47 & 54.66 & 165.14 & $163 \pm 1$ [69] \\
\hline \multirow[t]{2}{*}{$\mathrm{C}-\mathrm{C}_{\mathrm{X}}$} & (E)-ethanimine & 0.22 & -1.64 & 0.97 & 63.51 & 63.06 & 47.92 & \\
\hline & (E)-ethanaloxime & 0.24 & -1.35 & 0.93 & 67.94 & 67.76 & 51.49 & 48.42 [69] \\
\hline \multirow[t]{2}{*}{$\mathrm{C}-\mathrm{C}_{\mathrm{Y}}$} & (Z)-ethanimine & 0.22 & -1.56 & 0.98 & 51.72 & 51.36 & 39.02 & \\
\hline & (Z)-ethanaloxime & 0.26 & -1.43 & 0.92 & 57.18 & 56.92 & 43.25 & $40.51[69]$ \\
\hline
\end{tabular}

a in $\mathrm{H}_{2} \mathrm{O}$; sign not determined.

\section{Triplet instabilities and quasi-instabilities}

When restricted Hartree-Fock wave functions are used Hartree-Fock instabilities (or quasiinstabilities) arise each time the Hessian matrix, i.e. the principal propagator matrix at RPA level [53], has at least one negative (or positive but very small) eigenvalue, which implies that the molecule is predicted erroneously to have at least one negative (or positive but very small) excitation energy $E_{n}-E_{0}$ [37-44]. This problem is quite common for the two triplet contributions to the indirect nuclear spin-spin coupling constants, i.e. the Fermi contact and spin-dipolar term. It is due to the applied computational method and can lead to the overestimation of the corresponding contributions $\left\langle 0\left|\left(\hat{\vec{O}}_{A}^{F C}\right)_{\alpha}\right| n\right\rangle\left\langle n\left|\left(\hat{\vec{O}}_{B}^{F C}\right)_{\alpha}\right| 0\right\rangle /\left(E_{0}-E_{n}\right) \quad$ or $\left\langle 0\left|\left(\hat{\vec{O}}_{A}^{S D}\right)_{\alpha}\right| n\right\rangle\left\langle n\left|\left(\hat{\vec{O}}_{B}^{S D}\right)_{\alpha}\right| 0\right\rangle /\left(E_{0}-E_{n}\right)$ to the coupling constants in equation (1) if the product of the transitions moments for the Fermi contact contribution $\left\langle 0\left|\left(\hat{\vec{O}}_{A}^{F C}\right)_{\alpha}\right| n\right\rangle\left\langle n\left|\left(\hat{\vec{O}}_{B}^{F C}\right)_{\alpha}\right| 0\right\rangle$ or for the spin-dipolar contribution $\left\langle 0\left|\left(\hat{\vec{O}}_{A}^{S D}\right)_{\alpha}\right| n\right\rangle\left\langle n\left|\left(\hat{\vec{O}}_{B}^{S D}\right)_{\alpha}\right| 0\right\rangle$ is large for 
Table 2. Angle dependence of the reduced spin-spin couplings, $K$, (in $10^{19} \mathrm{~T}^{2} \mathrm{~J}^{-1}$ ) in $\mathrm{H}_{2} \mathrm{C}=\mathrm{NH}$ and $\mathrm{H}_{2} \mathrm{C}=\mathrm{NOH}$ calculated at SOPPA(CCSD) level.

\begin{tabular}{|c|c|c|c|c|c|c|c|}
\hline Coupling & Molecule & Angles in $\mathrm{H}_{2} \mathrm{C}=\mathrm{N}$ & $K^{\mathrm{OD}}$ & $K^{\mathrm{OP}}$ & $K^{\mathrm{SD}}$ & $K^{\mathrm{FC}}$ & $K$ \\
\hline \multirow[t]{4}{*}{${ }^{1} K(\mathrm{C}, \mathrm{N})$} & $\mathrm{H}_{2} \mathrm{C}=\mathrm{NH}$ & Optimized & 0.04 & -28.07 & 4.59 & 30.75 & 7.30 \\
\hline & & from $\mathrm{H}_{2} \mathrm{C}=\mathrm{NOH}$ & 0.03 & -28.63 & 4.47 & 30.26 & 6.17 \\
\hline & $\mathrm{H}_{2} \mathrm{C}=\mathrm{NOH}$ & Optimized & 0.14 & -26.71 & 8.20 & 30.62 & 12.25 \\
\hline & & from $\mathrm{H}_{2} \mathrm{C}=\mathrm{NH}$ & -0.13 & -26.28 & 8.32 & 31.50 & 13.68 \\
\hline \multirow[t]{4}{*}{${ }^{1} K\left(\mathrm{C}, \mathrm{H}_{\mathrm{X}}\right)$} & $\mathrm{H}_{2} \mathrm{C}=\mathrm{NH}$ & Optimized & 0.16 & -0.12 & 0.04 & 56.80 & 56.89 \\
\hline & & from $\mathrm{H}_{2} \mathrm{C}=\mathrm{NOH}$ & 0.16 & -0.13 & 0.04 & 58.08 & 58.16 \\
\hline & $\mathrm{H}_{2} \mathrm{C}=\mathrm{NOH}$ & Optimized & 0.20 & -0.01 & -0.01 & 58.72 & 58.90 \\
\hline & & from $\mathrm{H}_{2} \mathrm{C}=\mathrm{NH}$ & 0.20 & -0.00 & -0.01 & 57.66 & 57.84 \\
\hline \multirow[t]{4}{*}{${ }^{1} K\left(\mathrm{C}, \mathrm{H}_{\mathrm{Y}}\right)$} & $\mathrm{H}_{2} \mathrm{C}=\mathrm{NH}$ & Optimized & 0.16 & -0.09 & 0.05 & 52.86 & 52.99 \\
\hline & & from $\mathrm{H}_{2} \mathrm{C}=\mathrm{NOH}$ & 0.17 & -0.09 & 0.05 & 53.73 & 53.86 \\
\hline & $\mathrm{H}_{2} \mathrm{C}=\mathrm{NOH}$ & Optimized & 0.22 & -0.04 & 0.03 & 55.60 & 55.81 \\
\hline & & from $\mathrm{H}_{2} \mathrm{C}=\mathrm{NH}$ & 0.21 & -0.03 & 0.03 & 54.81 & 55.02 \\
\hline \multirow[t]{4}{*}{${ }^{2} K\left(\mathrm{~N}, \mathrm{H}_{\mathrm{X}}\right)$} & $\mathrm{H}_{2} \mathrm{C}=\mathrm{NH}$ & Optimized & -0.24 & -1.14 & 0.12 & 8.78 & 7.52 \\
\hline & & from $\mathrm{H}_{2} \mathrm{C}=\mathrm{NOH}$ & -0.23 & -1.18 & 0.13 & 7.77 & 6.49 \\
\hline & $\mathrm{H}_{2} \mathrm{C}=\mathrm{NOH}$ & Optimized & -0.17 & -1.13 & 0.05 & 11.10 & 9.85 \\
\hline & & From $\mathrm{H}_{2} \mathrm{C}=\mathrm{NH}$ & -0.18 & -1.09 & 0.04 & 12.09 & 10.85 \\
\hline \multirow[t]{4}{*}{${ }^{2} K\left(\mathrm{~N}, \mathrm{H}_{\mathrm{Y}}\right)$} & $\mathrm{H}_{2} \mathrm{C}=\mathrm{NH}$ & Optimized & -0.29 & -0.85 & 0.19 & -2.80 & -3.75 \\
\hline & & From $\mathrm{H}_{2} \mathrm{C}=\mathrm{NOH}$ & -0.28 & -0.93 & 0.19 & -2.36 & -3.37 \\
\hline & $\mathrm{H}_{2} \mathrm{C}=\mathrm{NOH}$ & Optimized & -0.23 & -0.99 & 0.06 & -1.74 & -2.90 \\
\hline & & From $\mathrm{H}_{2} \mathrm{C}=\mathrm{NH}$ & -0.25 & -0.89 & 0.07 & -1.94 & -3.00 \\
\hline \multirow[t]{4}{*}{${ }^{3} K\left(\mathrm{H}_{\mathrm{X}}, \mathrm{H}_{\mathrm{Y}}\right)$} & $\mathrm{H}_{2} \mathrm{C}=\mathrm{NH}$ & Optimized & -0.31 & 0.31 & 0.03 & 1.27 & 1.31 \\
\hline & & From $\mathrm{H}_{2} \mathrm{C}=\mathrm{NOH}$ & -0.34 & 0.34 & 0.02 & 1.74 & 1.77 \\
\hline & $\mathrm{H}_{2} \mathrm{C}=\mathrm{NOH}$ & Optimized & -0.32 & 0.34 & 0.02 & 0.66 & 0.69 \\
\hline & & From $\mathrm{H}_{2} \mathrm{C}=\mathrm{NH}$ & -0.05 & 0.31 & 0.03 & 0.23 & 0.28 \\
\hline
\end{tabular}

this excitation. Depending on the sign of these transition moments the total spin-spin coupling constant can become too large or too small. Using polarization propagator methods for the calculation of spinspin coupling constants as implemented in the DALTON program package [56], triplet instabilities (or quasi instabilities) can routinely be detected by a simultaneous calculation of the lowest eigenvalues of the principal propagator or Hessian matrix which is one of the strengths of propagator methods. In general it is possible to overcome this problem $[15,39-41,43,45,70]$ either by elimination of one of the two-electron integrals in the matrix element which causes the problem or removing or adding electronic correlation in the calculation. However, if one is aiming for a quantitative prediction of coupling constants comparable with experimental values, the mandatory option is to add more correlation to reach a better description of the excited states as well as the ground state [15]. 
Table 3. Two-bond (geminal) spin-spin couplings calculated at SOPPA(CCSD) level. Coupling constants, $J$, in $\mathrm{Hz}$ and reduced coupling constants, $K$, in $10^{19} \mathrm{~T}^{2} \mathrm{~J}^{-1}$.

\begin{tabular}{|c|c|c|c|c|c|c|c|c|}
\hline Coupling & Molecule & $K^{\mathrm{OD}}$ & $K^{\mathrm{OP}}$ & $K^{\mathrm{SD}}$ & $K^{\mathrm{FC}}$ & $K$ & $J$ & $J^{\text {expt. }}$ \\
\hline \multirow[t]{4}{*}{${ }^{15} \mathrm{~N}-\mathrm{H}_{\mathrm{X}}$} & methanimine & -0.24 & -1.14 & 0.12 & 8.78 & 7.52 & -9.16 & \\
\hline & (Z)-ethanimine & -0.20 & -1.01 & 0.10 & 10.04 & 8.93 & -10.88 & \\
\hline & methanaloxime & -0.17 & -1.13 & 0.05 & 11.10 & 9.85 & -12.00 & $-13.88[67]^{\mathrm{a}}$ \\
\hline & (Z)-ethanaloxime & -0.12 & -1.09 & 0.07 & 12.38 & 11.23 & -13.68 & $-15.93[67]^{b}$ \\
\hline \multirow[t]{4}{*}{${ }^{15} \mathrm{~N}-\mathrm{H}_{\mathrm{Y}}$} & methanimine & -0.29 & -0.85 & 0.19 & -2.80 & -3.75 & 4.56 & \\
\hline & (E)-ethanimine & -0.25 & -0.84 & 0.14 & -2.84 & -3.80 & 4.63 & \\
\hline & methanaloxime & -0.23 & -0.99 & 0.06 & -1.74 & -2.90 & 3.53 & $2.68[67]^{\mathrm{a}}$ \\
\hline & (E)-ethanaloxime & -0.19 & -1.05 & 0.02 & -2.08 & -3.30 & 4.02 & $2.93[67]^{\mathrm{b}}$ \\
\hline \multirow[t]{2}{*}{${ }^{15} \mathrm{~N}-\mathrm{C}_{\mathrm{X}}$} & (E)-ethanimine & -0.10 & -1.33 & 0.10 & 31.39 & 30.06 & -9.21 & \\
\hline & (E)-ethanaloxime & -0.05 & -0.44 & 0.13 & 31.91 & 31.55 & -9.67 & $|9.0|[68]^{c}$ \\
\hline \multirow[t]{2}{*}{${ }^{15} \mathrm{~N}-\mathrm{C}_{\mathrm{Y}}$} & (Z)-ethanimine & -0.14 & -2.27 & 0.11 & -11.72 & -14.01 & 4.29 & \\
\hline & (Z)-ethanaloxime & -0.10 & -1.54 & -0.05 & -4.98 & -6.68 & 2.05 & $|1.8|[68]^{\mathrm{c}}$ \\
\hline \multirow[t]{3}{*}{$\mathrm{C}-\mathrm{H}_{\mathrm{Z}}$} & methanimine & -0.26 & -0.86 & -0.02 & -3.58 & -4.72 & -14.26 & $-13.1[65]$ \\
\hline & (Z)-ethanimine & -0.21 & -0.90 & -0.03 & -3.40 & -4.55 & -13.74 & \\
\hline & (E)-ethanimine & -0.22 & -0.87 & -0.03 & -3.01 & -4.12 & -12.46 & \\
\hline \multirow[t]{2}{*}{$\mathrm{C}_{\mathrm{Y}}-\mathrm{H}_{\mathrm{X}}$} & (Z)-ethanimine & -0.12 & 0.06 & 0.01 & 5.00 & 4.94 & 14.94 & \\
\hline & (Z)-ethanaloxime & -0.13 & 0.08 & 0.01 & 2.58 & 2.54 & 7.68 & \\
\hline \multirow[t]{2}{*}{$\mathrm{C}_{X}-\mathrm{H}_{Y}$} & (E)-ethanimine & -0.12 & 0.05 & 0.01 & 4.47 & 4.42 & 13.34 & \\
\hline & (E)-ethanaloxime & -0.13 & 0.09 & 0.01 & 2.72 & 2.69 & 8.14 & \\
\hline \multirow[t]{2}{*}{$\mathrm{H}_{\mathrm{X}}-\mathrm{H}_{\mathrm{Y}}$} & Methanimine & -0.31 & 0.31 & 0.03 & 1.27 & 1.31 & 15.76 & $17.6[65]$ \\
\hline & methanaloxime & -0.32 & 0.34 & 0.02 & 0.66 & 0.69 & 8.33 & \\
\hline
\end{tabular}

a in $\mathrm{H}_{2} \mathrm{O}$.

$\mathrm{b}$ in $\mathrm{D}_{2} \mathrm{O}$.

${ }^{c}$ in $\mathrm{H}_{2} \mathrm{O}$; sign not determined.

Table 4. Three-bond (vicinal) spin-spin couplings calculated at SOPPA(CCSD) level. Coupling constants, $J$, in $\mathrm{Hz}$ and reduced coupling constants, $K$, in $10^{19} \mathrm{~T}^{2} \mathrm{~J}^{-1}$.

\begin{tabular}{llrrrrrrr}
\hline \multicolumn{1}{c}{ Coupling } & \multicolumn{1}{c}{ Molecule } & \multicolumn{1}{c}{$K^{\mathrm{OD}}$} & \multicolumn{1}{c}{$K^{\mathrm{OP}}$} & \multicolumn{1}{c}{$K^{\mathrm{SD}}$} & $K^{\mathrm{FC}}$ & \multicolumn{1}{c}{$K$} & $J$ & $J^{\text {expt. }}$ \\
\hline cis $-\mathrm{C}_{\mathrm{Y}}-\mathrm{H}_{\mathrm{Z}}$ & (Z)-ethanimine & -0.01 & -0.07 & -0.02 & 3.84 & 3.74 & 11.30 & \\
trans $-\mathrm{C}_{\mathrm{X}}-\mathrm{H}_{\mathrm{Z}}$ & (E)-ethanimine & -0.23 & 0.19 & 0.02 & 5.55 & 5.52 & 16.69 & \\
cis $-\mathrm{H}_{\mathrm{Y}}-\mathrm{H}_{\mathrm{Z}}$ & Methanimine & -0.07 & 0.02 & 0.01 & 1.53 & 1.48 & 17.80 & $17.0[65]$ \\
& (E)-ethanimine & -0.04 & -0.01 & 0.01 & 1.33 & 1.30 & 15.66 & \\
trans $-\mathrm{H}_{\mathrm{X}}-\mathrm{H}_{\mathrm{Z}}$ & Methanimine & -0.37 & 0.31 & 0.03 & 2.03 & 2.00 & 24.06 & $25.2[65]$ \\
& (Z)-ethanimine & -0.36 & 0.30 & 0.03 & 1.95 & 1.92 & 23.08 & \\
\hline
\end{tabular}


We found triplet quasi-instabilities at the RPA level in all the molecules studied here, yielding, in this way, meaningless results at this level of approximation.

\section{One-bond coupling}

In Table 1, our SOPPA(CCSD) results for the one-bond couplings are shown. The only important contribution to all one-bond coupling constants apart from the ${ }^{1} J(\mathrm{C}, \mathrm{N})$ coupling is the FC term. It is also the largest contribution to the ${ }^{1} J(\mathrm{C}, \mathrm{N})$ coupling followed by the OP term which is almost as large but opposite in sign. This implies that the SD term which is much larger than in all other couplings amounts to between $55 \%$ and $85 \%$ of the total ${ }^{l} J(\mathrm{C}, \mathrm{N})$ couplings. Similar large OP and SD terms were found previously for $\mathrm{N}_{2}$ and $\mathrm{CO}$ [15,71-76] and in $\mathrm{H}_{2} \mathrm{C}=\mathrm{CH}_{2}, \mathrm{H}_{2} \mathrm{C}=\mathrm{NH}, \mathrm{H}_{2} \mathrm{C}=\mathrm{O}$ and $\mathrm{H}_{2} \mathrm{C}=\mathrm{S}$ [16] but the near cancellation of the FC and OP terms seems to be a special feature of the $\mathrm{C}=\mathrm{N}$ moiety [16].

The $\mathrm{CH}_{3}$ and $\mathrm{OH}$ substituent effects on the ${ }^{1} J\left(\mathrm{C}, \mathrm{H}_{\mathrm{X} / \mathrm{Y}}\right)^{\dagger}$ and ${ }^{1} J\left(\mathrm{C}, \mathrm{C}_{\mathrm{Y}}\right)$ couplings change solely the FC contributions whereas in the case of the ${ }^{1} J\left(\mathrm{C}, \mathrm{C}_{\mathrm{X}}\right)$ and ${ }^{1} J\left(\mathrm{~N}, \mathrm{H}_{\mathrm{Z}}\right)$ couplings also the OP terms are affected. The behavior of the ${ }^{1} J(\mathrm{C}, \mathrm{N})$ coupling constants, on the other hand, differs again strongly from the other couplings. Here the largest changes are due to the $\mathrm{OH}$ substituent effect on the SD term $(\sim 3.5$ $\left.\times 10^{19} \mathrm{~T}^{2} \mathrm{~J}^{-1}\right)$ followed by changes in the FC term $\left(2.0-2.7 \times 10^{19} \mathrm{~T}^{2} \mathrm{~J}^{-1}\right)$ due to the $\mathrm{CH}_{3}$ substituent. The large $\mathrm{OH}$ substituent effect on the SD contribution to ${ }^{1} J(\mathrm{C}, \mathrm{N})$ stems from the fact that the SD term tends to be large for couplings across multiple bonds [15,16,71-76], as discussed above, and that the $\mathrm{OH}$ group exhibits a mesomeric $+\mathrm{M}$ effect [77] which modifies the $\pi$-system according to the resonance structures in Figure 4.

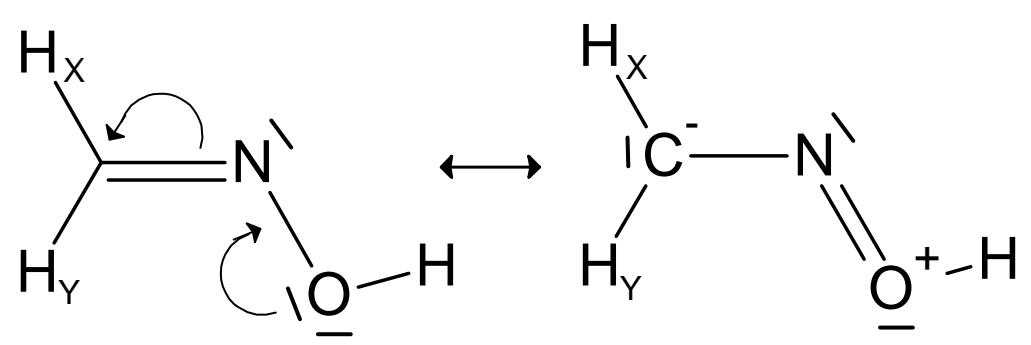

Figure 4. Resonance structures of methanaloxime 2.

From Table 2 we can see that $\mathrm{OH}$ substituent effect on the SD, FC and even the OP term becomes larger when we keep the angles in the $\mathrm{H}_{2} \mathrm{C}$ - group in $\mathbf{2}$ at the same values as in $\mathbf{1}$, i.e. there is also a geometry effect which opposes the mesomeric effect of the $\mathrm{OH}$ group. Furthermore, the $\mathrm{OH}$ substituent effect on the SD and OP terms is slightly larger in the (E) isomer 5 than in the (Z) isomer $\mathbf{6}$, but the opposite holds for the $\mathrm{OH}$ effect on the FC term. This shows that the inductive $+\mathrm{I}$ effect [77] of the $\mathrm{CH}_{3}$ group affects the three main contributions quite differently and depends on the position of the methyl-group relative to the nitrogen lone pair. This orientational effect for the $\mathrm{CH}_{3}$ substituent is most pronounced for the FC contribution to the ${ }^{l} J(\mathrm{C}, \mathrm{N})$ coupling constants, where the Fermi contact term is

$\dagger$ The subscripts $\mathrm{X}, \mathrm{Y}$ and $\mathrm{Z}$ are explained in Figures $1-3$. 
increased in the (E)-isomers, $\mathbf{3}$ and $\mathbf{5}$, and reduced in the $(\mathrm{Z})$ isomers, $\mathbf{4}$ and $\mathbf{6}$, of ethanimine and ethanaloxime. The difference in the FC terms between the $(\mathrm{E})$ and $(\mathrm{Z})$ isomers amounts therefore to $\sim 4.7 \times 10^{19} \mathrm{~T}^{2} \mathrm{~J}^{-1}$. In analogy to carbon-carbon or carbon-hydrogen one bond couplings [18,20] one should expect that the FC term is increased by the $\mathrm{CH}_{3}$ substituent, as indeed found for the (E) isomers. On the other hand we can see that the $\mathrm{C}-\mathrm{CH}_{3}$ bonds antiperiplanar (app) to the nitrogen lone pair, in $\mathbf{4}$ and 6, are slightly longer than the corresponding synperiplanar (spp) $\mathrm{C}-\mathrm{CH}_{3}$ bonds in $\mathbf{3}$ and 5, which should reduce the effect of the $\mathrm{CH}_{3}$ substituent in the $(\mathrm{Z})$ isomers. A deeper understanding of this orientational effect could be obtained from an analysis of the contributions of individual localized molecular orbitals as it was recently carried out for the one bond carbon-hydrogen and carbon-carbon coupling constants in methanimine [78] and acetoxime [79], respectively. It is also interesting to note that the $\mathrm{OH}$ and $\mathrm{CH}_{3}$ substituent effects on the $\mathrm{OP}$ contribution to the ${ }^{1} J(\mathrm{C}, \mathrm{N})$ coupling constants are not additive, i.e. the OP contributions are not significantly modified by the second substituent independent of its nature. The differences between the OP terms in $\mathbf{2}, \mathbf{3}, \mathbf{4 , 5}, \mathbf{6}$ and the OP term in $\mathbf{1}$ are therefore all $\sim 1.4 \times 10^{19} \mathrm{~T}^{2} \mathrm{~J}^{-1}$. Over all, the largest difference in the total ${ }^{1} J(\mathrm{C}, \mathrm{N})$ coupling constants, $4.95 \times 10^{19} \mathrm{~T}^{2} \mathrm{~J}^{-1}$, is observed between methanimine and methanaloxime where $3.61 \times 10^{19}$ $\mathrm{T}^{2} \mathrm{~J}^{-1}$ comes from the SD term.

Similar but smaller $\mathrm{CH}_{3}$ substituent effects are observed for the ${ }^{1} J\left(\mathrm{~N}, \mathrm{H}_{\mathrm{Z}}\right)$ coupling constants. The OP term is increased in both isomers by an equal amount, whereas the FC contribution is increased (reduced) by $\sim 0.7 \times 10^{19} \mathrm{~T}^{2} \mathrm{~J}^{-1}$ when the methyl group is synperiplanar (antiperiplanar) to the lone pair on nitrogen.

The ${ }^{1} J\left(\mathrm{C}, \mathrm{H}_{\mathrm{X} / \mathrm{Y}}\right)$ and ${ }^{1} J\left(\mathrm{C}, \mathrm{C}_{\mathrm{X} / \mathrm{Y}}\right)$ coupling constants exhibit the well known [17-21,80] orientational lone pair effect, which belongs to the A.3 category of Gil and Philipsborn [19]. Lone pair effects on ${ }^{1} J(\mathrm{C}, \mathrm{H})$ coupling constants, often called the Perlin effect [81], have been reported for many different types of molecules, e.g. oximes [66,82] and in particular six-membered rings [83,84]. The first observation of the lone pair effect on ${ }^{1} J(C, C)$ coupling constants was report for a series of oximes including the title compound ethanaloxime [69]. Previous semi-empirical [85,86] and DFT [79] calculations on acetoxime as well as DFT [78] and SOPPA(CCSD) [16] calculations on methanimine showed that only the FC contribution is changed by the lone pair effect. Furthermore an analysis of the contributions of individual localized DFT molecular orbitals to the FC term in the same molecules $[78,79]$ indicated that this effect is primarily due to a direct lone pair contribution from the corresponding localized orbital, which is positive for the coupling synperiplanar to the lone pair and negative for the coupling antiperiplanar to it. On the other hand, the indirect lone pair contribution via a charge transfer or hyperconjugation interaction from the nitrogen non-bonding lone pair orbital to the antibonding carbon-carbon orbital, the so-called anomeric effect [22-24], appeared to be less important $[18,78,79]$. The effect of various substituents on experimental ${ }^{1} J(C, C)$ coupling constants in imines and oximes has also been studied [18] and an empirical relation between the electronegativity of the substituents and the ${ }^{1} J(\mathrm{C}, \mathrm{C})$ coupling constants in imines and oximes has even been derived $[87,18]$. 
In the present work we are primarily interested in changes in the lone pair effect on ${ }^{1} J(\mathrm{C}, \mathrm{H})$ and ${ }^{1} J(\mathrm{C}, \mathrm{C})$ due to the $\mathrm{OH}$ and $\mathrm{CH}_{3}$ substituents. For methanimine our theoretical difference, $\Delta^{1} K_{\mathrm{C}-\mathrm{H}_{\mathrm{X} / \mathrm{Y}}}^{\mathrm{Th}}={ }^{1} K\left(\mathrm{C}, \mathrm{H}_{\mathrm{X}}\right)-{ }^{1} K\left(\mathrm{C}, \mathrm{H}_{\mathrm{Y}}\right)=3.90 \times 10^{19} \mathrm{~T}^{2} \mathrm{~J}^{-1}$, agrees very nicely with the experimental value $[65,66]$ of $3.00 \times 10^{19} \mathrm{~T}^{2} \mathrm{~J}^{-1}$. The corresponding values of $\Delta^{1} K_{\mathrm{C}-\mathrm{H}_{\mathrm{X} / \mathrm{Y}}}^{\mathrm{Th}}$ in methanaloxime, ethanimine and ethanaloxime are 3.09, 3.30 and $3.28 \times 10^{19} \mathrm{~T}^{2} \mathrm{~J}^{-1}$. This means that the Perlin effect is reduced by the $\mathrm{OH}$ and $\mathrm{CH}_{3}$ substituent. The $\mathrm{OH}$ substituent leads to an increase of the ${ }^{1} K(\mathrm{C}, \mathrm{H})$ coupling constants but more so for the couplings antiperiplanar to the nitrogen lone pair. The main electronic mechanism behind these changes should be the mesomeric $+\mathrm{M}$ effect of the $\mathrm{OH}$ group (see Figure 4), because the pure inductive -I effect of an electronegative substituent like $\mathrm{OH}$ [77] should reduce the $\mathrm{C}-\mathrm{H}_{\mathrm{Y}}$ couplings [19]. However, the $\mathrm{OH}$ substituent effect is smaller, if one keeps the angles in the $\mathrm{H}_{2} \mathrm{C}$ moiety fixed (see Table 2), which indicates that there is also a small geometrical contribution.

Furthermore, replacing the other hydrogen by a methyl group reduces the ${ }^{1} K(\mathrm{C}, \mathrm{H})$ couplings and the corresponding $\angle_{\mathrm{HCN}}$ angles. This $\mathrm{CH}_{3}$ effect is larger for the imines than for the oximes but there is no general trend with respect to the position of the methyl group. For the imines the effect is larger when the $\mathrm{CH}_{3}$ group is antiperiplanar to the lone pair and for the oximes when it is synperiplanar. In addition to the inductive $+\mathrm{I}$ effect of the $\mathrm{CH}_{3}$ group one should expect also a contribution from the changes in the $\angle_{\mathrm{HCN}}$ angle. Contreras and Peralta [21] have shown that the ${ }^{1} J(\mathrm{C}, \mathrm{H})$ couplings anti-and synperiplanar to the nitrogen lone pair in methylamine are reduced by reducing the corresponding $\angle_{\mathrm{HCN}}$ angles but more for the synperiplanar arrangement which leads to a reduction of the Perlin effect. In order to get an idea of the importance of this effect for imines we have performed four additional SOPPA(CCSD) calculations on 1 where we have altered the $\angle_{\mathrm{H}_{\mathrm{X}} \mathrm{CN}}$ and $\angle_{\mathrm{H}_{\mathrm{Y}} \mathrm{CN}}$ angles independently by $\sim 5^{\circ}$. The results are presented in Figure 5 . We can see that both ${ }^{l} K(\mathrm{C}, \mathrm{H})$ coupling constants are reduced when the corresponding $\angle_{\mathrm{HCN}}$ angles are reduced. However, a closer analysis shows that this can only account for about $50 \%$ of the $\mathrm{CH}_{3}$ substituent effect. The rest must be due to the inductive effect.

In the ethanimines, $\mathbf{3}$ and $\mathbf{4}$, and -oximes, $\mathbf{5}$ and $\mathbf{6}$, the same trends are observed for the ${ }^{1} J\left(\mathrm{C}, \mathrm{C}_{\mathrm{X} / \mathrm{Y}}\right)$ and ${ }^{1} J\left(\mathrm{C}, \mathrm{H}_{\mathrm{X} / \mathrm{Y}}\right)$ coupling constants. However the orientational lone pair effect, $\Delta^{1} K_{\mathrm{C}-\mathrm{C}_{\mathrm{X} / \mathrm{Y}}}^{\mathrm{Th}}=11.70 \times 10^{19}$ $\mathrm{T}^{2} \mathrm{~J}^{-1}$ for ethanimine and $10.84 \times 10^{19} \mathrm{~T}^{2} \mathrm{~J}^{-1}$ for ethanaloxime, as well as the $\mathrm{OH}$ substituent effect, $4.70 / 5.56 \times 10^{19} \mathrm{~T}^{2} \mathrm{~J}^{-1}$ for the $(\mathrm{E}) /(\mathrm{Z})$ isomers, are much larger. Overall we can state that the orientational lone pair effects are significantly altered in magnitude but not in sign by the $\mathrm{OH}$ and $\mathrm{CH}_{3}$ substituents. 

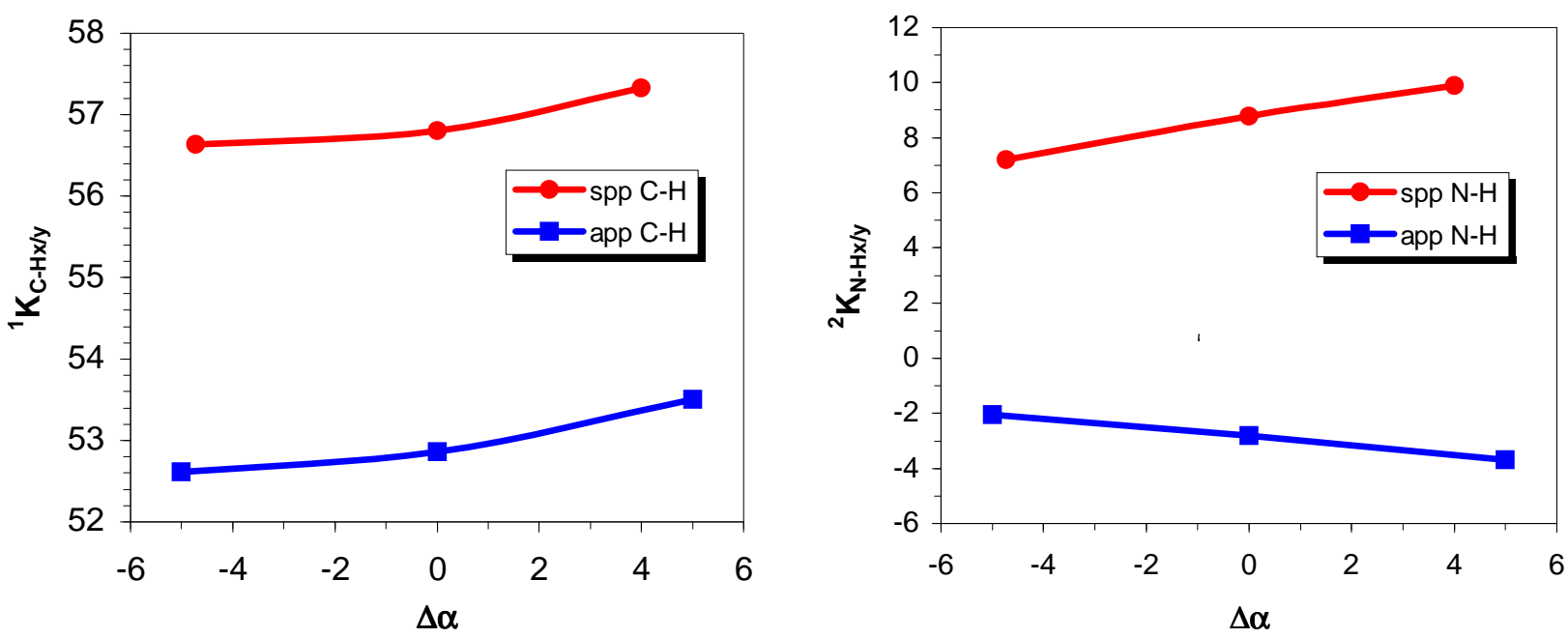

Figure 5. Calculated dependence of the ${ }^{1} K\left(\mathrm{C}, \mathrm{H}_{\mathrm{X} / \mathrm{Y}}\right)$ and ${ }^{2} K\left(\mathrm{~N}, \mathrm{H}_{\mathrm{X} / \mathrm{Y}}\right)$ couplings (in $\left.10^{19} \mathrm{~T}^{2} \mathrm{~J}^{-1}\right)$ on deviations of the $\angle_{\mathrm{H}_{\mathrm{X}} \mathrm{CN}}$ and $\angle_{\mathrm{H}_{\mathrm{Y}} \mathrm{CN}}$ angles, $\alpha$, from their equilibrium value.

\section{Two-bond coupling}

Analyzing the four contributions to the two-bond couplings, Table 3, one can observe that the Fermi contact term is always the largest contribution. Nevertheless, the orbital paramagnetic term is also important for all geminal couplings involving nitrogen and for the ${ }^{2} K\left(\mathrm{C}, \mathrm{H}_{\mathrm{Z}}\right)$ coupling constants. It amounts to between $4 \%$ and $34 \%$ of the total constants for these couplings. The largest values are found for the ${ }^{2} K\left(\mathrm{~N}, \mathrm{H}_{\mathrm{X}} / \mathrm{C}_{\mathrm{X}}\right)$ couplings synperiplanar to the lone pair of nitrogen. One can also see that the changes in the total reduced couplings are almost entirely due to the FC contribution with the exception of the ${ }^{2} K\left(\mathrm{~N}, \mathrm{C}_{\mathrm{X}}\right)$ coupling constants where the variation in the OP term accounts for $60 \%$ of $\mathrm{OH}$ substituent effect.

We find a strong lone pair effect for the geminal ${ }^{2} K(\mathrm{~N}, \mathrm{H})$ and ${ }^{2} K(\mathrm{~N}, \mathrm{C})$ couplings synperiplanar and antiperiplanar to the nitrogen lone pair. This orientational lone pair effect on geminal couplings was probably first observed in propanaloxime [88] and was later categorized as B.3 by Gil and Philipsborn [19]. It is much stronger than the corresponding effect on the one bond couplings in Table 1. The reduced couplings synperiplanar to the lone pair become all positive, whereas the antiperiplanar couplings are negative. The spplapp differences $\left(\Delta^{2} K_{\mathrm{N}-\mathrm{H}_{\mathrm{X} Y}^{\mathrm{Th}}}={ }^{2} K\left(\mathrm{~N}, \mathrm{H}_{\mathrm{X}}\right)-{ }^{2} K\left(\mathrm{~N}, \mathrm{H}_{\mathrm{Y}}\right)=11.27,12.75\right.$, 12.73 and $14.53 \times 10^{19} \mathrm{~T}^{2} \mathrm{~J}^{-1}$ for $\mathbf{1}, \mathbf{2}, \mathbf{3 / 4}$ and 5/6) are also much larger than for the one-bond couplings. Similarly to the one-bond couplings, the geminal ${ }^{2} K\left(\mathrm{~N}, \mathrm{C}_{\mathrm{X} / \mathrm{Y}}\right)$ couplings are larger and more sensitive to the lone pair effect than the ${ }^{2} K(\mathrm{~N}, \mathrm{H})$ couplings, the differences being $\Delta^{2} K_{\mathrm{N}-\mathrm{C}_{\mathrm{X} / \mathrm{Y}}}^{\mathrm{Th}}=44.07$ and $38.23 \times 10^{19} \mathrm{~T}^{2} \mathrm{~J}^{-1}$ for $\mathbf{3 / 4}$ and $\mathbf{5 / 6}$, respectively. Comparison with the corresponding experimental differences $\Delta^{2} K_{\mathrm{N}-\mathrm{H}_{X / Y}}^{\text {Exp }}=13.60 \times 10^{19} \mathrm{~T}^{2} \mathrm{~J}^{-1}$ in $2, \Delta^{2} K_{\mathrm{N}-\mathrm{H}_{X / Y}}^{\operatorname{Exp}}=15.48 \times 10^{19} \mathrm{~T}^{2} \mathrm{~J}^{-1}$ and $\Delta^{2} K_{\mathrm{N}-\mathrm{C}_{X / Y}}^{\text {Exp }}=35.26 \times$ $10^{19} \mathrm{~T}^{2} \mathrm{~J}^{-1}$ in $\mathbf{5 / 6}$ proofs again the quality of our calculations. 
The $\mathrm{OH}$ substituent effect makes the geminal ${ }^{2} K(\mathrm{~N}, \mathrm{H})$ and ${ }^{2} K(\mathrm{~N}, \mathrm{C})$ couplings more positive, as it also was the case for the one-bond ${ }^{l} K(\mathrm{C}, \mathrm{H})$ and ${ }^{l} K(\mathrm{C}, \mathrm{C})$ couplings. However, for the $a p p{ }^{2} K\left(\mathrm{~N}, \mathrm{H}_{\mathrm{Y}}\right)$ couplings this effect $\left(0.50\right.$ or $\left.0.85 \times 10^{19} \mathrm{~T}^{2} \mathrm{~J}^{-1}\right)$ is significantly smaller than for the $\operatorname{spp}{ }^{2} K\left(\mathrm{~N}, \mathrm{H}_{\mathrm{X}}\right)$ couplings $\left(\sim 2.3 \times 10^{19} \mathrm{~T}^{2} \mathrm{~J}^{-1}\right)$ and the analogous one-bond couplings $\left(2.0-2.9 \times 10^{19} \mathrm{~T}^{2} \mathrm{~J}^{-1}\right)$. For the two-bond ${ }^{2} K(\mathrm{~N}, \mathrm{C})$ couplings the $\mathrm{OH}$ effect is still positive but is now larger for the coupling antiperiplanar to the lone pair $\left(7.33 \times 10^{19} \mathrm{~T}^{2} \mathrm{~J}^{-1}\right)$ than for the spp coupling $\left(1.49 \times 10^{19} \mathrm{~T}^{2} \mathrm{~J}^{-1}\right)$. This implies that in the ethane derivatives, where the differences between the $\mathrm{OH}$ effects on spp and app couplings are largest, the effect of the $\mathrm{OH}$ group is larger in the $(\mathrm{Z})$ than in the $(\mathrm{E})$ isomer and thus larger when the methyl group is cis to the $\mathrm{OH}$ group. Furthermore, we can see from Table 2 that the $\mathrm{OH}$ effect on the $\operatorname{spp}{ }^{2} \mathrm{~K}\left(\mathrm{~N}, \mathrm{H}_{\mathrm{X}}\right)$ coupling is larger in a calculation on $\mathrm{H}_{2} \mathrm{C}=\mathrm{NOH}$ with the $\mathrm{H}_{2} \mathrm{C}=\mathrm{N}$ angles taken from $\mathrm{H}_{2} \mathrm{C}=\mathrm{NH}$ than in a calculation with optimized geometries for both molecules. This shows that there is an geometrical or angle effect opposing the pure electronic effect of the $\mathrm{OH}$ group, in contrast to the findings for the analogous one-bond ${ }^{l} K\left(\mathrm{C}, \mathrm{H}_{\mathrm{X}}\right)$ coupling constants. However, for the app couplings we cannot detect a corresponding effect.

The $\mathrm{CH}_{3}$ substituent effect increases the numerical values of the geminal ${ }^{2} K\left(\mathrm{~N}, \mathrm{H}_{\mathrm{X} / \mathrm{Y}}\right)$ coupling constants and the spplapp differences, contrary to the case of the one-bond coupling constants. In order to separate the pure electronic inductive effect from the effect of the changes in the $\angle_{\mathrm{H}_{\mathrm{X} Y \mathrm{CN}}}$ angles we have also carried out four additional SOPPA(CCSD) calculations for the geminal couplings in 1 where we have altered the $\angle_{\mathrm{H}_{\mathrm{X}} \mathrm{CN}}$ and $\angle_{\mathrm{H}_{\mathrm{Y}} \mathrm{CN}}$ angles independently by $\sim 5^{\circ}$. We can see from the results, in Figure 5, that the absolute values of the geminal ${ }^{2} K\left(\mathrm{~N}, \mathrm{H}_{\mathrm{X} / \mathrm{Y}}\right)$ coupling constants and thus the spp/app difference decreases with a reduction of the corresponding $\angle_{\mathrm{H}_{\mathrm{X} / \mathrm{YN}}}$ angle. This implies that the electronic and angle effects due the $\mathrm{CH}_{3}$ group are opposing each other which contrasts the $\mathrm{CH}_{3}$ effect on the one-bond couplings. One might therefore estimate that the pure inductive effect of the methyl group is even larger than observed in the differences between $\mathbf{3 / 4}$ and $\mathbf{1}$.

For the $\mathrm{C}-\mathrm{H}_{\mathrm{Z}}$ coupling we find a slightly larger $\mathrm{CH}_{3}$ substituent effect on the (E) isomer, i.e. when the methyl group is trans to the coupling pathway.

The geminal ${ }^{2} K\left(\mathrm{C}_{\mathrm{X}}, \mathrm{H}_{\mathrm{Y}}\right)$ and ${ }^{2} K\left(\mathrm{C}_{\mathrm{Y}}, \mathrm{H}_{\mathrm{X}}\right)$ coupling constants in $\mathbf{3}$ and $\mathbf{4}$ and the corresponding ${ }^{2} K\left(\mathrm{H}_{\mathrm{Y}}, \mathrm{H}_{\mathrm{Y}}\right)$ coupling constant in $\mathbf{1}$ are approximately reduced to half of their values by the $\mathrm{OH}$ substituent effect. In the case of the latter coupling we can see from Table 2 that the pure electronic effect of the $\mathrm{OH}$ group is again larger than the observed difference between $\mathbf{2}$ and 1, i.e. the geometrical or angle contribution is again opposing the electronic effect as observed for the other geminal couplings.

\section{Three-bond coupling}

The three-bond or vicinal couplings, in Table 4, are mainly dominated by the Fermi contact term and its variations. As for the other couplings we observe that the reduced couplings involving carbon 
are larger than the corresponding coupling constants with hydrogen. The largest reduced vicinal coupling constants and changes are therefore observed for ethanimine. The reduced trans couplings are a factor of $\sim 1.4$ larger than the corresponding cis couplings in very good agreement with the experimental observed ratio of 1.48 for $\mathbf{1}$.

\section{Conclusions}

We have theoretically investigated all four contributions to the reduced indirect spin-spin coupling constant of $\mathrm{H}_{2} \mathrm{C}=\mathrm{NH}, \mathrm{H}_{2} \mathrm{C}=\mathrm{N}-\mathrm{OH}$ and the stereoisomers of ethanimine and ethanaloxime at the SOPPA(CCSD) level using the aug-cc-pVTZ-J basis sets. Our calculated coupling constants and differences between them agree very well with the available experimental data. In preliminary calculations at the RPA level we have observed triplet instabilities for all the molecules studied here.

The Fermi contact term is the largest contribution to all the couplings studied here. Nevertheless, the orbital paramagnetic term is also important for the geminal coupling constants involving nitrogen and in particular for the one-bond carbon-nitrogen coupling across the double bond, where it is equal in magnitude to the FC term but of opposite sign. Furthermore the spin-dipolar term is unusually large for this coupling and accounts for $40 \%$ to $85 \%$ of the total coupling. Changes in the coupling constants due to the methyl or hydroxyl groups as well as the differences between coupling constants synperiplanar and antiperiplanar to the lone pair of nitrogen are also dominated by the Fermi contact term. Again the spin-dipolar and orbital paramagnetic terms are also important for the $\mathrm{OH}$ substituent effect on the one bond and two-bond nitrogen-carbon couplings.

Comparison of $K(\mathrm{C}, \mathrm{H})$ coupling constants with the corresponding $K(\mathrm{C}, \mathrm{C})$ couplings in the ethane analogs shows that the geminal and vicinal reduced couplings involving carbon are between twice and four times as large as the hydrogen couplings. This holds also for stereoelectronic effects of the nitrogen lone pair such as the Perlin effect, its two-bond analog and the cis-trans vicinal couplings.

The $\mathrm{CH}_{3}$ and $\mathrm{OH}$ substituents have some important implications on the coupling constants. In general the changes due to the hydroxyl group are larger as one might expect. The $\mathrm{OH}$ substituent gives a positive contribution to all couplings with the exception of the geminal ${ }^{2} K(\mathrm{H}, \mathrm{H})$ and ${ }^{2} K(\mathrm{C}, \mathrm{H})$ couplings in the methylene and ethyliden moieties where the couplings are reduced by more or less a factor of two. This is a pure electronic effect given that in methanimine the geminal ${ }^{2} K\left(\mathrm{H}_{\mathrm{X}}, \mathrm{H}_{\mathrm{Y}}\right)$ coupling increases when the $\angle_{\mathrm{H}_{\mathrm{X}} \mathrm{CH}_{\mathrm{Y}}}$ angle increases. In the one-bond ${ }^{1} K(\mathrm{C}, \mathrm{N})$ coupling the $\mathrm{OH}$ substituent affects most strongly the spin-dipolar term. On the other hand, we do not observe a strong orientational effect of the $\mathrm{OH}$ group, i.e. its contributions to coupling pathways synperiplanar or antiperiplanar to the hydroxyl group do not differ in sign but only in magnitude. The $\mathrm{OH}$ group leads also to changes in the bond angles in such a way that the angle between the hydrogens in the methylene moiety or the hydrogen and the methyl group in the ethyliden moiety is widened. We tried therefore to separate this angle effect from the electronic effects by additional calculations where the bond angles where not changed. These calculations show that the angle part of the $\mathrm{OH}$ changes is 
opposite to the pure electronic $\mathrm{OH}$ effect for the one-bond ${ }^{1} K(\mathrm{C}, \mathrm{N})$ and all geminal couplings, whereas they have the same sign for the one-bond ${ }^{1} K(\mathrm{C}, \mathrm{C} / \mathrm{H})$ couplings. We propose that the $\mathrm{OH}$ substituent effect on the one-bond coupling is mainly due to a resonance or mesomeric $+\mathrm{M}$ effect according to Figure 4 , because we observe large changes in the spin-dipolar contribution to the one-bond ${ }^{1} K(\mathrm{C}, \mathrm{N})$ couplings, which are reduced by the additional electropositive methyl group. Furthermore, according to Gil and Philipsborn [19] the one-bond ${ }^{1} K(\mathrm{C}, \mathrm{C} / \mathrm{H})$ couplings and the geminal ${ }^{1} K(\mathrm{~N}, \mathrm{C} / \mathrm{H})$ coupling constants synperiplanar to the $\mathrm{OH}$ group should be reduced, if the $\mathrm{OH}$ effect would be mainly inductive.

The methyl group leads to some distinct changes in the orientational lone pair effects. For example, the one-bond ${ }^{1} K(\mathrm{~N}, \mathrm{C})$ and ${ }^{1} K(\mathrm{~N}, \mathrm{H})$ coupling constants are increased when the methyl group is syn to the lone pair on nitrogen and reduced when it is in anti position. This effect is, however, only half as large for the ${ }^{1} K(\mathrm{~N}, \mathrm{C})$ couplings. A similar orientational effect is observed for the geminal ${ }^{2} K(\mathrm{~N}, \mathrm{H})$ coupling constants but with the opposite sign, i.e. the couplings are reduced when the methyl group is syn to the lone pair and increase in anti position. No orientational effect is observed for the corresponding one-bond ${ }^{1} K(\mathrm{C}, \mathrm{H})$ couplings; they are always reduced by the methyl group. Similar to the $\mathrm{OH}$ substituent, the $\mathrm{CH}_{3}$ substituent leads to changes in the bond angles in the $\mathrm{H}_{2} \mathrm{C}=\mathrm{N}$ moiety although in a different way. The whole $\mathrm{H}_{3} \mathrm{CCH}$ group is rotated to give space for the methyl group. Analyzing therefore the calculated dependence of the one-bond ${ }^{1} K(\mathrm{C}, \mathrm{H})$ and geminal ${ }^{2} K(\mathrm{~N}, \mathrm{H})$ couplings on their respective $\angle_{\mathrm{HCN}}$ angles shows that the angle contribution amounts to about half of the total $\mathrm{CH}_{3}$ effect on the one-bond ${ }^{1} K\left(\mathrm{C}, \mathrm{H}_{\mathrm{X} / \mathrm{Y}}\right)$ couplings, whereas it has the opposite sign as the observed $\mathrm{CH}_{3}$ effect for the geminal ${ }^{2} K\left(\mathrm{~N}, \mathrm{H}_{\mathrm{X} / \mathrm{Y}}\right)$ couplings.

Finally the lone pair contribution is always more positive for synperiplanar than for antiperiplanar couplings independent of the number of bonds which separate the coupled nuclei. Nevertheless we find that the stereoelectronic effects of the nitrogen lone pair on one bond couplings are significantly reduced by the $\mathrm{OH}$ and $\mathrm{CH}_{3}$ substituents whereas the corresponding differences between geminal coupling constants are increased showing that the errors introduced by making model systems can indeed be important.

\section{Acknowledgments}

This research was made possible by CPU time grants from the Danish Natural Science Research Council and from the Danish Center for Scientific Computing, which provided for the necessary computer time on Danish supercomputer facilities. Financial support from the Danish Natural Science Research Council, the Carlsberg foundation and from SGCyT-UNNE of Argentina is greatly acknowledged. We wish to thank also CONICET and ANPCyT for providing partial support (grants PIP-0649/98 and BID/OC-AR-PICT-00604, respectively). 


\section{References and Notes}

1. See the Nobel Prize in Chemistry 2002 : http://www.nobel.se/chemistry/laueates/2002

2. Alkorta, I.; Elguero, J. Int. J. Mol. Sci. 2003, 4, ??-??.

3. Scheurer, C.; Brüschweiler, R. J. Am. Chem. Soc. 1999, 121, 8661-8662.

4. Del Bene, J. E.; Perera, S. A.; Bartlett, R. J. J. Am. Chem. Soc. 2000, 122, 3560-3561.

5. Pecul, M.; Leszczynski, J.; Sadlej, J. J. Phys. Chem. A. 2000, 104, 8105-8113.

6. Del Bene, J. E.; Bartlett, R. J. J. Am. Chem. Soc. 2000, 122, 10480-10481.

7. Bagno, A. Chem.-Eur. J. 2000, 6, 2925-2930.

8. Czernek, J.; Brüschweiler, R. J. Am. Chem. Soc. 2001, 123, 11079-11080.

9. Del Bene, J. E.; Perera, S. A.; Bartlett, R. J. Magn. Res. Chem. 2001, 39, S109-S114.

10. Barfield, M. J. Am. Chem. Soc. 2002, 124, 4158-4168.

11. Del Bene, J. E.; Perera, S. A.; Bartlett, R. J.; Elguero, J.; Alkorta, I.; López-Leonardo, C.; Alajarin, M. J. Am. Chem. Soc. 2002, 124, 6393-6397.

12. Provasi, P. F.; Aucar, G. A.; Sauer, S. P. A. J. Chem. Phys. 2000, 112, 6201-6208.

13. Sauer, S. P. A.; Provasi, P. F.; Aucar, G. A. to be published.

14. Helgaker, T.; Jaszuński, M.; Ruud, K.; Górska, A. Theor. Chem. Acc. 1998, 99, 175-182.

15. Enevoldsen, T.; Oddershede, J.; Sauer, S. P. A. Theor. Chem. Acc. 1998, 100, 275-284.

16. Provasi, P. F.; Aucar, G. A.; Sauer, S. P. A. J. Chem. Phys. 2001, 115, 1324-1334.

17. Hansen, P. E. Prog. NMR Spectrosc. 1981, 14, 175-296.

18. Krivdin, L. B.; Kalabin, G. A. Prog. NMR Spectrosc. 1989, 21, 293-448.

19. Gil, V. M. S.; von Philipsborn, W. Magn. Res. Chem. 1989, 27, 409-430.

20. Kamieńska-Trela, K. Annual Reports on NMR Spectroscopy 1995, 30, 131-230.

21. Contreras, R. H.; Peralta, J. E. Prog. NMR Spectrosc. 2000, 37, 321-425.

22. Kirby, A. J., The Anomeric Effect and Related Stereoelectronic Effects at Oxygen, Springer Verlag: Berlin, 1983.

23. Juaristi, E.; Cuevas, G., The Anomeric Effect, CRC Press: Boca Raton, 1995.

24. Reed, A.; Schleyer, P. v. R. J. Am. Chem. Soc. 1990, 112, 1434-1445.

25. Sauer, S. P. A. J. Phys. B: At. Mol. Opt. Phys. 1997, 30, 3773-3780.

26. Wigglesworth, R. D.; Raynes, W. T.; Sauer, S. P. A.; Oddershede, J. Molec. Phys. 1997, 92, 77-88.

27. Wigglesworth, R. D.; Raynes, W. T.; Sauer, S. P. A.; Oddershede, J. Molec. Phys. 1998, 94, 851862.

28. Sauer, S. P. A.; Møller, C. K.; Koch, H.; Paidarová, I.; Špirko, V. Chem. Phys. 1998, 238, 385-399.

29. Kirpekar, S.; Sauer, S. P. A. Theor. Chem. Acc. 1999, 103, 146-153.

30. Wigglesworth, R. D.; Raynes, W. T.; Kirpekar, S.; Oddershede, J.; Sauer, S. P. A. J. Chem. Phys. 2000, 112, 3735-3746.

31. Sauer, S. P. A.; Raynes, W. T. J. Chem. Phys. 2000, 113, 3121-3129.

32. Grayson, M.; Sauer, S. P. A. Mol. Phys. 2000, 98, 1981-1990.

33. Sauer, S. P. A.; Raynes, W. T.; Nicholls, R. A. J. Chem. Phys. 2001, 115, 5994-6006.

34. Thouless, D. J., The Quantum Mechanics of Many-Body Systems, Academic Press: New York, 1961.

35. Čížek, J.; Paldus, J. J. Chem. Phys. 1967, 47, 3976-3985.

36. Chambaud, G.; Levy, B.; Millie, P. Theo. Chim. Acta. 1978, 48, 103-118. 
37. Scuseria, G. E.; Contreras, R. H. Theo. Chim. Acta. 1981, 59, 437-450.

38. Scuseria, G. E.; Engelmann, A. R.; Contreras, R. H. Theo. Chim. Acta. 1982, 61, 49-57.

39. Scuseria, G. E.; Contreras, R. H. Chem. Phys. Lett. 1982, 93, 425-428.

40. Righini, R.; Giribet, C. G.; Ruiz de Azúa, M. C.; Contreras, R. H. J. Mol. Struct. (Theochem). 1990, 210, 199-204.

41. Aucar, G. A.; Contreras, R. H. J. Magn. Reson. 1991, 93, 413-418.

42. Contreras, R. H.; Ruiz de Azúa, M. C.; Giribet, C. G.; Aucar, G. A.; Loboyan de Bonczok, R. J. Mol. Struct. (Theochem). 1993, 284, 249-269.

43. Lobayan, R. M.; Aucar, G. A., J. Mol. Struct. (Theochem). 1998, 452, 1-11.

44. Lobayan, R. M.; Aucar, G. A., J. Mol. Struct. (Theochem). 1998, 452, 13-23.

45. Scuseria, G. E.; Geertsen, J.; Oddershede, J. J. Chem. Phys. 1989, 90, 2338-2343.

46. Peng, H. W. Proc. Roy. Soc. London A. 1941, 178, 499-505.

47. McLachlan, A. D.; Ball, M. A. Rev. Mod. Phys. 1964, 36, 844-855.

48. Rowe, D. J. Rev. Mod. Phys. 1968, 40, 153-166.

49. Nielsen, E. S.; Jørgensen, P.; Oddershede, J. J. Chem. Phys. 1980, 73, 6238-6246.

50. Ramsey, N. F. Phys. Rev. 1953, 91, 303-307.

51. Mills, I.; Cvitaš, T.; Homann, K.; Kallay, N.; Kuchitsu, K. Quantities, Units; Symbols in Physical Chemistry, Blackwell Scientific Publications: Oxford, 1993.

52. Sauer, S. P. A. J. Chem. Phys. 1993, 98, 9220-9221.

53. Oddershede, J. Adv. Quantum Chem. 1978, 2, 275-352.

54. Sauer, S. P. A.; Packer, M. J. The ab initio calculation of molecular properties other than the potential energy surface, in Computational Molecular Spectroscopy; Bunker, P. R.; Jensen, P., Eds.; John Wiley; Sons: London, 2000, chapter 7, pages 221--252.

55. Geertsen, J.; Oddershede, J. Chem. Phys. 1984, 90, 301-311.

56. DALTON, an electronic structure program, Release 1.2: Helgaker, T.; Jensen, H. J. Aa.; Jørgensen, P.; Olsen, J.; Ruud, K.; Ågren, H.; Auer, A. A.; Bak, K. L.; Bakken, V.; Christiansen, O.; Coriani, S.; Dahle, P.; Dalskov, E. K.; Enevoldsen, T.; Fernandez, B.; Hättig, C.; Hald, K.; Halkier, A.; Heiberg, H.; Hettema, H.; Jonsson, D.; Kirpekar, S.; Kobayashi, R.; Koch, H.; Mikkelsen, K. V.; Norman, P.; Packer, M. J.; Pedersen, T. B.; Ruden, T. A.; Sanchez, A.; Saue, T.; Sauer, S. P. A.; Schimmelpfennig, B.; Sylvester-Hvid, K. O.; Taylor, P. R.; Vahtras, O.; http://www.kjemi.uio.no/software/dalton/dalton.html, 2001.

57. The aug-cc-pVTZ-J basis sets can be found at http://fyskem.ki.ku.dk/sauer/basissets.

58. Dunning Jr., T. H.; J. Chem. Phys. 1989, 90, 1007-1023.

59. Kendall, R. A.; Dunning, T. H.; Harrison, R. J. J. Chem. Phys. 1992, 96, 6796-6806.

60. Geertsen, J.; Oddershede, J.; Raynes, W. T.; Scuseria, G. E. J. Magn. Reson. 1991, 93, 458-471.

61. Guilleme, J.; San Fabián, J. J. Chem. Phys. 1998, 109, 8168-8181.

62. Gaussian 98, Revision A.7: Frisch, M. J.; Trucks, G. W.; Schlegel, H. B.; Scuseria, G. E.; Robb, M. A.; Cheeseman, J. R.; Zakrzewski, V. G.; Montgomery, J. A.; Stratmann, R. E., Jr.; Burant, J. C.; Dapprich, S.; Millam, J. M.; Daniels, A. D.; Kudin, K. N.; Strain, M. C.; Farkas, O.; Tomasi, J.; Barone, V.; Cossi, M.; Cammi, R.; Mennucci, B.; Pomelli, C.; Adamo, C.; Clifford, S.; Ochterski, J.; Petersson, G. A.; Ayala, P. Y.; Cui, Q.; Morokuma, K.; Malick, D. K.; Rabuck, A. D.; Raghavachari, K.; Foresman, J. B.; Cioslowski, J.; Ortiz, J. V.; Baboul, A. G.; Stefanov, B. B.; 
Liu, G.; Liashenko, A.; Piskorz, P.; Komaromi, I.; Gomperts, R.; Martin, R. L.; Fox, D. J.; Keith, T.; Al-Laham, M. A.; Peng, C. Y.; Nanayakkara, A.; Gonzalez, C.; Challacombe, M.; Gill, P. M. W.; Johnson, B.; Chen, W.; Wong, M. W.;;res, J. L., Gonzalez, C.; Head-Gordon, M.; Replogle, E. S.; Pople, J. A.; Gaussian, Inc.: Pittsburgh PA, 1998.

63. Lovas, F. J.; Suenram, R. D.; Johnson, D. R.; Clark, F. O.; Tiemann. E. J. Chem. Phys. 1980, 72, 4964-4972.

64. Mills, I.; Cvitaš, T.; Homann, K.; Kallay, N.; Kuchitsu, K. Quantities, Units; Symbols in Physical Chemistry, Blackwell Scientific Publications: Oxford, 1993.

65. Braillon, B.; Lasne, M. C.; Ripoll, J. L.; Denis, J. M. Nouv. J. Chim. 1982, 6, 121-122.

66. Yonezawa, T.; Morishima, I. J. Mol. Spectrosc. 1968, 27, 210-217.

67. Crépaux, D.; Lehn, J. M.; Dean, R. R. Mol. Phys. 1969, 16, 225-239.

68. Lichter, R. L.; Dorman, D. E.; Wasylishen, R. J. Am. Chem. Soc. 1974, 96, 930-932.

69. Wray, V. Progress in NMR Spectroscopy. 1979, 13, 177-256.

70. Gomez, C. A.; Provasi, P. F.; Aucar, G. A. J. Mol. Struct. (THEOCHEM) submitted.

71. Oddershede, J.; Jørgensen, P.; Beebe, N. H. F. Chem. Phys. 1977, 25, 451-458.

72. Geertsen, J.; Oddershede, J.; Scuseria, G. E. J. Chem. Phys. 1987, 87, 2138-2142.

73. Vahtras, O.; Ågren, H.; Jørgensen, P.; Helgaker, T.; Aa. Jensen, H. J. Chem. Phys. Lett. 1993, 209, 201-206.

74. Malkin, V. G.; Malkina, O. L.; Salahub, D. R. Chem. Phys. Lett. 1994, 221, 91-99.

75. Perera, S. A.; Sekino, H.; Bartlett, R. J. J. Chem. Phys. 1994, 101, 2186-2191.

76. Auer, A. A.; Gauss, J. J. Chem. Phys. 2001, 115, 1619-1622.

77. See e.g. March, J., Advanced Organic Chemistry: Reactions, Mechanisms, and Strcuture, John Wiley \& Sons: New York, 1985.

78. Zaccari, D. G.; Snyder, J. P.; Peralta, J. E.; Taurian, O. E.; Contreras, R. H.; Barone, V. Mol. Phys. 2002, 100, 705-715.

79. Barone, V.; Peralta, J. E.; Contreras, R. H.; Sosnin, A. V.; Krivdin, L. B. Magn. Reson. Chem. 2001, 39, 600-606.

80. Contreras, R. H.; Giribet, C. G.; Ruiz de Azúa, M. C.; Cavasotto, C. N.; Aucar, G. A.; Krivdin, L. J. Mol. Struct. (Theochem). 1990, 210, 175-186.

81. Wolfe, S.; Pinto, B. M.; Varma, V.; Leung, R. Y. N. Can. J. Chem. 1990, 68, 1051-1062.

82. Yonezawa, T.; Morishima, I.; Fukuta, K.; Ohmori, Y. J. Molec. Spectrosc. 1969, 31, 341-345.

83. Perlin, A. S.; Casu, B. Tetrahedron Lett. 1969, 2921-2924.

84. Cuevas, G.; Juaristi, E. J. Am. Chem. Soc. 2002, 124, 13088-13096.

85. Zinchenko, S. V.; Kiselev, R. Yu.; Krivdin, L. B. Zh. Org. Khim.. 1991, 27, 1233-1239.

86. Krivdin, L. B.; Zinchenko, S. V.; Kalabin, G. A.; Facelli, J. C.; Tufró, M. F.; Contreras, R. H.; Denisov, A. Yu.; Gavrilyuk, O. A.; Mamatyuk, V. I. J. Chem. Soc. Faraday Trans. 1992, 88, 2459-2463.

87. Krivdin, L. B., Shcherbakov, V. V.; Kalabin, G. A. Zh. Org. Khim. 1986, 22, 342-348.

88. Kintzinger, J. P.; Lehn, J. M. Chem. Commun. 1967, 660-661.

(C) 2003 by MDPI (http://www.mdpi.org). Reproduction for noncommercial purposes permitted. 